\title{
Life Domain Satisfactions as Predictors of Overall Life Satisfaction Among Workers: Evidence from Chile
}

\author{
Nicolas Loewe $\cdot$ Mehdi Bagherzadeh $\cdot$ Luis Araya-Castillo • \\ Claudio Thieme $\cdot$ Joan Manuel Batista-Foguet
}

Accepted: 15 July 2013/Published online: 1 October 2013

(C) Springer Science+Business Media Dordrecht 2013

\begin{abstract}
This article examines the subjective antecedents of life satisfaction of workers. Adopting a 'bottom-up' perspective, we assessed the unique influence that satisfaction with multiple life domains have on evaluative judgments of overall life satisfaction. Based on a nationwide sample of 530 Chilean workers, we simultaneously tested the effects of seven life domain satisfactions that have been consistently included in extant models of life satisfaction and subjective well-being. These were satisfaction with health, financial situation, social relationships, one's self-worth, leisure-time, family, and work. Having controlled for age and gender, results showed that satisfaction with one's financial situation was the dominant predictor of overall life satisfaction of workers, with a weight of 36 . Satisfaction with family, work, and health had effects of $.25, .14$, and .14, respectively. Interestingly, satisfaction with one's self-worth, leisure-time, and social relationships did not have statistically significant effects on life satisfaction, although the first two showed $t$ values near the critical value.
\end{abstract}

N. Loewe $(\bowtie) \cdot$ J. M. Batista-Foguet

Leadership Development Research Centre (GLEAD), ESADE Business School, Ramon Llull University, Av. Torre Blanca, 59, 08172 Sant Cugat del Vallès, Spain

e-mail: nicolas.loewe@esade.edu

J. M. Batista-Foguet

e-mail: joanm.batista@esade.edu

M. Bagherzadeh

Institute for Innovation and Knowledge Management (IIK), ESADE Business School, Ramon Llull University, Sant Cugat del Vallès, Spain

e-mail: mehdi.bagherzadehniri@esade.edu

L. Araya-Castillo

Observatory of Spanish Multinational Companies (OEME)/Department of Strategy and General Management, ESADE Business School, Ramon Llull University, Sant Cugat del Vallès, Spain e-mail: luis.araya.castillo@gmail.com

C. Thieme

Facultad de Economía y Empresa, Universidad Diego Portales, Santiago, Chile

e-mail: claudio.thieme@udp.cl 
Keywords Life satisfaction · Workers - Life domains - Subjective well-being · Chile

\section{Introduction}

Traditionally, there have been two theoretical approaches to the concept of life satisfaction, which differ in the causal assumptions: the 'bottom-up' and 'top-down' perspectives (Diener 1984; Headey et al. 1991; Lance et al. 1989). The 'bottom-up' perspective assumes that a person's overall life satisfaction depends on his or her satisfaction in many concrete areas of life, which can be classified into broad life domains such as family, friendship, work, leisure, and the like (Pavot and Diener 2008; Heller et al. 2004; Veenhoven 1996). Multiple discrepancy theory (Michalos 1985), need hierarchy theory (Maslow 1970), and the self-concordance model (Sheldon and Elliot 1999) are all good examples of 'bottomup' theories that conceive domain satisfactions as needs. According to these theories the more needs are satisfied, the greater the satisfaction with life as a whole. From the 'bottomup' perspective, domain satisfactions mediate the effects of situational factors on life satisfaction. The 'top-down' perspective is a dispositional explanation, which contends that differences in personality and other stable traits of the person predispose people to be differentially satisfied with their lives (Diener et al. 2003; Steel et al. 2008; DeNeve and Cooper 1998). Defendants of the 'top-down' perspective rather than denying the influence of situational factors (Diener 1996), claim that both dispositional and situational factors interact in relation to life satisfaction (Brief et al. 1993; Heller et al. 2004).

'Top-down' and 'bottom-up' perspectives have often been presented as competing theories; however, both approaches are not incongruent when dispositional factors are viewed as more distal predictors of life satisfaction than domain satisfactions (Erdogan et al. 2012). The dispositions of each person influence his or her perceptions of environmental conditions, resulting in more or less satisfaction with life domains. Thus, personality has a distal effect on global life satisfaction according to this integrating approach (Brief et al. 1993). For instance, a meta-analysis by Heller et al. (2004) showed that job and marital satisfactions mediate the effect of personality on life satisfaction. Erdogan et al. (2012) claimed that the 'treating personality as a distal predictor in models of life satisfaction may be more consistent with theory as opposed to treating it as a control variable that needs to be partialled out.' We focus on the closest predictors in the causality chain in this article.

Drawing from the 'bottom-up' perspective, subjective well-being (SWB) researchers have put forth a myriad of life domain satisfactions, which are thought to be relevant to overall life satisfaction. Among the life domains that have generated more consensus are satisfaction with health, family, income, social relationships, leisure-time, work, sex life, housing, safety, self-worth, and education (e.g., Flanagan 1978; Argyle 2001; Headey and Wearing 1992; Greenley et al. 1997; Praag et al. 2003; Costa 2008). Although these essential life domains may be generalised among most people, there is evidence that people from different cultures (Diener 2000; Diener and Suh 2000; Diener and Lucas 2000) and in distinct developmental life stages (Cantor and Blanton 1996; Cantor and Sanderson 1999) weigh life domains differently when asked to judge their global life satisfaction.

Different cultures usually weigh life domains differently because culture shapes individual attitudes, values, and the types of goals individuals pursue (Hofstede 1991; Kim 1994), which in turn determine the specific life domains people consider relevant, and the weight they give to each domain (Oishi et al. 1999; Kasser and Ryan 1993, 1996; Cantor 
and Sanderson 1999). For example, East Asian cultures tend to be self-critical societies, where modesty and self-improvement is highly valued (Markus and Kitayama 1991). In these cultures past personal accomplishments are not evaluated as positively as in the U.S. (Heine et al. 1999; Markus and Kitayama 1991) because the concept of life satisfaction is based primarily on external conditions and current status rather than past accomplishments. Cross-cultural differences in life satisfaction have been primarily explained in terms of the broad cultural variable of a society's degree of individualism-collectivism (Triandis 1989) or independent-interdependent concepts of the self (Markus and Kitayama 1991). In individualistic societies such as the US and Western Europe people are oriented toward their personal goals and desires and are more likely to attribute success and failure to themselves. In contrast, people in collectivist cultures view the group as of primary importance and individuals are willing to sacrifice their desires to the will of the group. When individualistic and collectivistic nations are compared in terms of different indicators of SWB, more individualistic nations generally report higher mean levels of life satisfaction (Diener and Diener 1995).

However, the weights that people give to multiple life domains also change during life (Cantor and Blanton 1996; Cantor and Sanderson 1999). Domain satisfactions relevant to salient life tasks are more strongly related to global life satisfaction than less relevant domain satisfactions (Harlow and Cantor 1996). For example, building an intimate relationship is a salient life task during young adulthood; as a result, young adults tend to attribute relatively high importance to satisfaction with romantic relationships when assessing their global life satisfaction (Oishi et al. 1999). Given the cross-cultural differences in conceptualisations of life satisfaction and the different weights attributed to life domains in different life stages, SWB researchers have usually studied relatively homogeneous populations that share to some extent the same values, salient life tasks, and cultural context (e.g., Bretones and Gonzalez 2011; Ku et al. 2008; Brown and Tierney 2009).

SBW researchers have tended to focus on nonworking populations-such as children (Huebner 1994), adolescents (Gilman and Huebner 2000), students (Seligson et al. 2003), and those with health problems (e.g., Matthews et al. 2012)-leaving the satisfaction of workers to other research fields (Diener et al. 1999) such as management and industrial/ organisational (I/O) psychology. In turn, these fields have usually defined a satisfied worker as someone satisfied with their job and scant attention has been paid to the more holistic concept of workers' life satisfaction (Erdogan et al. 2012). Recently, some research has shown preliminary evidence that life satisfaction may have a similar predictive power than that of work satisfaction in predicting some important organisational outcomes such as job performance (Jones 2006; Greguras and Diefendorff 2010; Duckworth et al. 2009); job commitment (Vanaki and Vagharseyyedin 2009; Redman and Snape 2006; Susskind et al. 2000); absenteeism (Murphy et al. 2006; Judge and Locke 1993); turnover (Shaw and Gupta 2001; De Cuyper et al. 2009); early retirement intentions (Von Bonsdorff et al. 2010); and employee burnout (Haar and Roche 2010). While research accumulates showing the organisational consequences of workers being more satisfied with their life, less is known about the how different life domains contribute to the overall life satisfaction of workers. Gaining further understanding of how workers weigh multiple life domains in the formation of their life satisfaction evaluative judgments will provide organisations with a more holistic view of their workers - and the associated organisational outcomes - and is also important because two-thirds of the world population are workers (World Bank Indicators 2012). Accordingly, we examine the subjective predictors of life satisfaction of workers in Chile.

Chile is an emerging economy that has experienced remarkably rapid economic growth and significant societal changes over the past 30 years. The average annual growth rate of 
the gross domestic product (GDP) reached $6 \%$ from 1980 to 2012. The Human Development Index (HDI) - a composite statistic of life expectancy, education, and income indices that rank countries into four tiers of human development and published by the united nations development programme (UNDP)—showed an increase for Chile from .630 in 1980 to .819 in 2011 (UNDP Human Development Report 2013). This remarkable increase ranks Chile in the first place of Latin American countries and 40th place worldwide in terms of living conditions (UNDP Human Development in Chile 2012). This rapid development has been accompanied of low unemployment rates, of $7 \%$ on average. In this context, organisations increasingly need to better understand worker perceptions, aspirations, and motivations, in order to increase their employee retainment rates and performance indicators.

The article is organised as follows: firstly, we identify a number of life domains that previous research found to be relevant to the life satisfaction of most working adults. Secondly, we develop measures for the multiple domain satisfactions. Thirdly, we examine the relevance that a sample of Chilean workers attribute to different domain satisfactions in the formation of their global life satisfaction evaluative judgments. Finally, we discuss the pattern of weights obtained and interpret the results-while placing a special emphasis on the cultural context of Chile.

\section{Model of Life Satisfaction}

The number of life domains likely to be relevant to someone's life satisfaction can range from a small number to an almost infinite recount of spheres of being (Rojas 2006; Cummins 1996). However, according to the compatibility principle, the relationship between two variables increases when both are assessed at the same level of specificity (Fishbein and Ajzen 1974). Given that life satisfaction is a broad concept, then life domains will probably need to be relatively broad as well. Rojas (2006) suggested that partitions of a human life must value parsimony, should relate to the way people think about their lives, and be useful to the understanding of life satisfaction. For the purpose of this study we selected seven life domain satisfactions that SWB research has consistently identified as relevant to life satisfaction: health, financial situation, social relationships, self-worth, leisure-time, family, and work. Other domains such as sex life, education, and safety have also received considerable attention in the literature (e.g., Headey and Wearing 1992; Cummins 1996; Sirgy et al. 2010); however, we did not include them in our model for the sake of parsimony. Without pretending to be an exhaustive list, Table 1 summarises how the seven selected life domains have been represented in extant models of life satisfaction and SBW. We only considered the direct effects of the multiple domains on life satisfaction, although the authors are aware of the possible modes of interaction among life domains (Wilensky 1960; Judge and Watanabe 1994; Wu 2009). Also, we assumed that domains had additive effects on life satisfaction. Finally, given that the focus of our research are the subjective predictors of life satisfaction we did not draw hypotheses for age and gender-although both were incorporated as control variables.

\section{Methods}

By combining deductive and inductive approaches (Hinkin 1995), we developed measures of satisfaction for the seven life domains hypothesised to predict overall life satisfaction. 
Table 1 Life domains in previous studies

\begin{tabular}{|c|c|c|c|c|c|c|c|}
\hline & Health & Finance & Social & Self & Leisure & Family & Work \\
\hline Flanagan (1978) & - & - & - & & & - & - \\
\hline Andrews and Inglehart (1979) & - & - & - & & - & & - \\
\hline Headey et al. (1991) & • & & & & - & & - \\
\hline Zapf and Glatzer (1987) & - & - & & & - & - & - \\
\hline Day (1987) & - & • & - & - & - & - & - \\
\hline Headey and Wearing 1992 & - & - & - & & - & - & - \\
\hline Felce and Perry (1995) & - & - & - & - & - & - & - \\
\hline Cummins (1996) & $\bullet$ & $\bullet$ & & & & & \\
\hline Alfonso et al. (1996) & & & - & - & & - & - \\
\hline Greenley et al. (1997) & $\bullet$ & $\bullet$ & $\bullet$ & & $\bullet$ & & \\
\hline \multicolumn{8}{|l|}{ Möller and Saris (2001) } \\
\hline Gregg and Salisbury (2001) & - & - & - & - & & - & - \\
\hline Argyle (2001) & $\bullet$ & $\bullet$ & $\bullet$ & & $\bullet$ & & $\bullet$ \\
\hline Praag et al. (2003) & $\bullet$ & $\bullet$ & & & $\bullet$ & & $\bullet$ \\
\hline Cummins et al. (2003) & $\bullet$ & & $\bullet$ & $\bullet$ & & $\bullet$ & \\
\hline Costa (2008) & $\bullet$ & $\bullet$ & $\bullet$ & & & & \\
\hline Sirgy et al. (2010) & - & - & - & & - & - & - \\
\hline
\end{tabular}

Exploratory and confirmatory factor analyses were then used to refine the measures and assess their psychometric properties. Finally, using structural equation modelling, we estimated the effect sizes of the multiple life domain satisfactions on overall life satisfaction. We controlled the potential influence of age and gender. Common method variance was also evaluated.

\subsection{Measures}

To assess overall life satisfaction we used satisfaction with life scale (SWLS; Diener et al. 1985), which has been one of the most widely used scales for the measurement of the construct. Research has established acceptable psychometric properties for SWLS, including high internal consistency, test-retest reliability, and convergent validity (for reviews, see Pavot and Diener 1993, 2008; Vassar 2008; Diener 1994). SWLS has been applied and validated in many different cultural settings and with different socio-demographic groups of people (Gadermann et al. 2011; Oishi 2006; Pons et al. 2002; Durak et al. 2010). Participants indicated their responses in a 5-point Likert scale labelled from 1 'completely disagree' to 5 'completely agree'.

Measures of satisfaction with health, financial situation (finance), social relationships (social), one's self-worth (self), leisure-time (leisure), family, and work were created. To generate the specific items reflecting the different life domains we drew inspiration from previous research (e.g., Flanagan 1978; Cummins 1996; Huebner 1994; Felce and Perry 1995; Alfonso et al. 1996; Gregg and Salisbury 2001). The number of indicators used to reflect the satisfaction with life domains varied between two and four items across life domains. In total, 24 items were generated in Spanish and general recommendations for item formulation, such as avoiding double-barrelled questions and requests including implicit assumptions (Saris and Galhofer 2007) were followed. Once items were generated 
for representing the focal constructs, we evaluated their content validity. We adopted a qualitative approach to assess the content adequacy of life domain satisfaction measures. In so doing, we conducted in-depth interviews with a dozen Chilean workers, who were asked to associate questionnaire items to life domains (Hinkin and Tracey 1999; MacKenzie et al. 2011). Interestingly, these interviews revealed that some interviewes associated item Q13 ('I feel I have vitality, energy') to self-worth, rather than to health, as was intended. Also as a result of the in-depth interviews, item Q19 ('I have a good relationship with everyone at work') was incorporated to broaden our work satisfaction measure. The items were then discussed with two subject matter experts, and three items were dropped for not being applicable to all participants or lacking face validity. Unfortunately, these items could not be reworded or replaced because data collection had already started. In sum, the item generation process resulted in the 21 indicators presented in Table 3, which shows the English version of the items after having confirmed their accuracy using the standard backtranslation technique (Breslin 1970). The items were arranged in a battery of questions headed by the request for an answer of 'to what extent do you agree or disagree with the following statements:' Research participants responded on the same 5-point Likert scale used for SWLS. For the actual administration of the battery, the items were sorted to alternate the latent life domains. We placed the SWLS items preceding the battery including the satisfaction with life domains to avoid what Kahneman et al. (2006) called focusing illusion. According to these authors, individuals tend to inflate their scores on important factors for their well-being, when questions on satisfaction with life domains precede reports on their own well-being.

\subsection{Sample and Procedure}

The measures used in this study were incorporated in a longer questionnaire administered to investigate several characteristics of the Chilean population. A total of 1,500 people were sampled to represent the total population of Chile with a $5 \%$ sampling error. Using the Chilean census, participants were sampled from different country regions, where the Greater Santiago region was overrepresented. Some $30 \%$ of the centres of population (i.e., cities and towns) and districts were selected proportionally. Blocks, housings, and individuals were randomly selected. A team of professional canvassers went door-to-door for 3 weeks to personally administer the survey questionnaire to the sampled participants. Out of the 1,500 participants in the study 530 individuals declared themselves to be employed when the questionnaire was administered, and were suitable for this study. This sample size assured a respondents-to-items ratio of 19.6:1, almost twice the minimum ratio of 10:1 recommended by many authors (e.g., Hu et al. 1992; Hair et al. 2006). In the effective

Table 2 Sample characteristics $(\mathrm{N}=530)$

\begin{tabular}{|c|c|c|c|c|c|c|c|}
\hline Age & & Marital status & & Education & & Occupation & \\
\hline Less than 25 & $11.1 \%$ & Married & $53.9 \%$ & No education & $3.6 \%$ & Self-employed & $35.7 \%$ \\
\hline From 25 to 34 & $25.1 \%$ & Single & $27.0 \%$ & Primary & $18.2 \%$ & Employee & $64.3 \%$ \\
\hline From 35 to 44 & $25.7 \%$ & Living together & $13.4 \%$ & Secondary & $54.7 \%$ & & \\
\hline From 45 to 54 & $24.0 \%$ & Separated & $4.0 \%$ & University & $22.9 \%$ & & \\
\hline From 55 to 65 & $11.5 \%$ & Divorced & $1.0 \%$ & $\mathrm{PhD}$ & $.6 \%$ & & \\
\hline More than 65 & $2.6 \%$ & Widow/er & $.8 \%$ & & & & \\
\hline
\end{tabular}


Table 3 Mean and standard deviations for items

\begin{tabular}{|c|c|c|c|c|}
\hline Life domain & Item code & Item & Mean & $\mathrm{SD}$ \\
\hline \multirow[t]{4}{*}{ Health } & Q1 & My health is excellent & 3.63 & 1.00 \\
\hline & Q2 & I get sick more often than others & 2.27 & .87 \\
\hline & $\mathrm{Q}^{\text {(a) }}$ & I am in good shape & 3.50 & .89 \\
\hline & Q13 ${ }^{\text {(a) }}$ & I feel I have vitality, energy & 4.07 & .73 \\
\hline \multirow[t]{3}{*}{ Finance } & Q5 & I am satisfied with my economic situation & 3.29 & 1.00 \\
\hline & Q6 & I am satisfied with what I can buy & 3.45 & .97 \\
\hline & $\mathrm{Q} 17^{(\mathrm{a})}$ & I am satisfied with my income & 3.34 & 1.12 \\
\hline \multirow[t]{2}{*}{ Social } & Q8 & I am satisfied with the friends I have & 3.96 & .87 \\
\hline & Q9 & I am satisfied with my social life & 3.95 & .82 \\
\hline \multirow[t]{4}{*}{ Self } & Q4 & I am self-confident & 4.12 & .70 \\
\hline & Q10 & I consider myself a fulfilled person & 3.75 & .92 \\
\hline & Q11 & I feel valued, respected & 4.15 & .70 \\
\hline & $\mathrm{Q} 12^{(\mathrm{b})}$ & I feel proud of what I have achieved till now & 4.12 & .71 \\
\hline \multirow[t]{2}{*}{ Leisure } & Q14 & I am satisfied with the amount of free-time I have & 3.31 & 1.10 \\
\hline & Q15 & I am satisfied with the activities I do in my free-time & 3.56 & 1.00 \\
\hline \multirow[t]{2}{*}{ Family } & Q7 & I am satisfied with my family life & 4.11 & .76 \\
\hline & Q21 & I am satisfied with the relationship with my partner & 4.13 & .76 \\
\hline \multirow[t]{4}{*}{ Work } & Q16 & I like the work I do & 3.98 & .84 \\
\hline & Q18 & I am satisfied with the responsibility I have in my work & 3.91 & .76 \\
\hline & Q19 $9^{(\mathrm{b})}$ & I have a good relationship with everyone at work & 4.03 & .71 \\
\hline & $\mathrm{Q} 20^{(\mathrm{b})}$ & My salary is adequate to my experience and responsibility & 3.36 & 1.14 \\
\hline \multirow[t]{5}{*}{ SWLS } & LS1 & In most ways my life is close to my ideal & 3.46 & .84 \\
\hline & LS2 & The conditions of my life are excellent & 3.24 & .89 \\
\hline & LS3 & I am satisfied with my life & 3.73 & .77 \\
\hline & LS4 & So far I have got the important things I want in my life & 3.69 & .82 \\
\hline & LS5 & If I could live my life over, I would change almost nothing & 3.18 & 1.06 \\
\hline
\end{tabular}

Q2 is reverse coded

a Item eliminated in exploratory factor analysis

b Item eliminated in confirmatory factor analysis

sample $(\mathrm{N}=530), 35.7 \%$ of the participants were self-employed while $64.3 \%$ were employees, either from the public or private sector. The age of participants ranged from 18 to 74 years, with a median of 39 years and an average age of 40.3 years $(\mathrm{SD}=12.7)$; $68.3 \%$ were men and $31.7 \%$ women; $53.9 \%$ were married; and $78.2 \%$ had secondary education or higher. Table 2 provides detailed sample characteristics.

\section{Results}

\subsection{Analysis}

We first conducted an exploratory data analysis. None of the variables had more than $3 \%$ of missing values, and these were randomly distributed across cases without any pattern (Olinsky et al. 2003). To avoid the listwise deletion method omitting cases with any missing 
values - with the associated reduction in sample size and power of tests-30 missing values were imputed using expectation maximisation criterion in SPSS (Roth 1994). Table 3 reports the mean and the standard deviation of the items. Skewness and kurtosis tests rejected the univariate normality of most of the variables and Mardia's (1974) test rejected multivariate normality of the data. This calls for robust estimation methods to improve the correctness of standard errors and test statistics under violation of distributional assumptions. Satorra-Bentler scaled $\chi 2$ (Satorra and Bentler 1994) was used to assess global goodness of fit in CFA. As a further precaution, we relied on other global goodness of fit indices to evaluate the extent to which the relationships hypothesised in the standard CFA model were consistent with the sample data (Hu and Bentler 1999). After taking these precautions, non-normality of data was not an issue. We then conducted an exploratory factor analysis (EFA) - using unweighted least squares and promax rotation criteria- to examine the dimensionality of the multiple measures. As a result of this analysis, items Q3, Q10, Q13, and Q17 were dropped because they showed low reliability when loaded on an unintended dimension, or when cross-loaded on two factors (Fornell and Larcker 1981). Interestingly, the EFA results confirmed what had been raised from previous in-depth interviews, namely, that some research participants associated Q13 ('I feel I have vitality, energy') with health domain; while others associated the question with self-worth.

We then tested the relevance of domain satisfaction effects using structural equation modelling. We used LISREL 8.7 (Jöreskog and Sörbom 2001) to estimate the model's parameters and goodness of fit indices. After an initial estimation of the measurement model—using maximum likelihood criterion-we followed a process of model refinement in which modifications were introduced in the model one at a time. As a result of this process, items Q12, Q19, and Q20 were pruned because they showed non-hypothesised cross-loadings that were strong and significant (Batista and Coenders 2000; Bollen 1989; Hair et al. 2006). We did not have to release any constraint of the standard confirmatory factor analysis model (CFA). The resulting measurement model showed adequate goodness of fit indices. In particular, a set of global fit indices assessing absolute fit, $\chi^{2}=285$ $\left(d f=146 ; \quad \chi^{2} / d f=1.95\right), \quad \mathrm{RMSEA}=.032, \quad$ and $\mathrm{SRMR}=.034, \quad$ and relative fit, $\mathrm{CFI}=.989$ and NFI $=.969$, provided evidence in favour of the validity of the measurement model (Hu and Bentler 1999; MacKenzie et al. 2011). In addition to the assessment of the model global fit indices, a detailed examination of the standardised residual and modification indices also suggested that the measurement model appropriately reproduced the covariance matrix. The two largest positive standardised residuals had a value of between 2 and 3 . None of the modification indices suggested showed a significant decrease in $\chi^{2}$.

Based on the results of the CFA, we assessed the psychometric properties of the different measures. Item reliabilities ranged from .25 to $.91(\mathrm{M}=.6 ; \mathrm{SD}=.18)$. Only two items, Q2 and Q4, showed reliabilities lower than the desirable threshold value of .50, which suggests that the indicator accounts for most of the variance (Fornell and Larcker 1981). Table 4 reports construct reliabilities, all of which-except satisfaction with one's self-worth (.56) — exceeded, or were near to, the threshold value of .70 that is commonly accepted for newly developed measures (Nunnally and Bernstein 1994). To assess convergent validity of the life domains we examined the average variances extracted (AVE), shown also in Table 4. Finally, we confirmed acceptable levels of discriminant validity by examining whether the AVE for each life domain was greater than the square of the correlation between the domains (Fornell and Larcker 1981).

To test our model of life satisfaction we estimated the structural model shown in Fig. 1. The multiple predictors accounted for a $70.5 \%$ of the variance of overall life satisfaction. 
Table 4 Reliabilities, average variances extracted, correlations, squared correlations, ${ }^{a}$ and variance inflation factors

\begin{tabular}{llllllllllll}
\hline & Reliability & AVE & LS & Health & Finance & Social & Self & Leisure & Family & Job & VIF \\
\hline LS & .74 & .38 & 1 & & & & & & & & \\
Health & .64 & .58 & .38 & 1 & .02 & .04 & .05 & .05 & .06 & .08 & 1.39 \\
Finance & .84 & .73 & .67 & .16 & 1 & .12 & .24 & .14 & .13 & .25 & 1.81 \\
Social & .78 & .66 & .51 & .20 & .36 & 1 & .31 & .15 & .23 & .16 & 1.78 \\
Self & .56 & .43 & .64 & .23 & .49 & .56 & 1 & .15 & .36 & .23 & 1.75 \\
Leisure & .78 & .65 & .46 & .23 & .37 & .39 & .39 & 1 & .10 & .11 & 1.43 \\
Family & .75 & .61 & .61 & .26 & .37 & .49 & .60 & .32 & 1 & .08 & 1.47 \\
Work & .66 & .50 & .55 & .29 & .50 & .41 & .48 & .34 & .30 & 1 & 2.10 \\
\hline
\end{tabular}

${ }^{\text {a }}$ Values over the diagonal indicate squared Pearson correlations

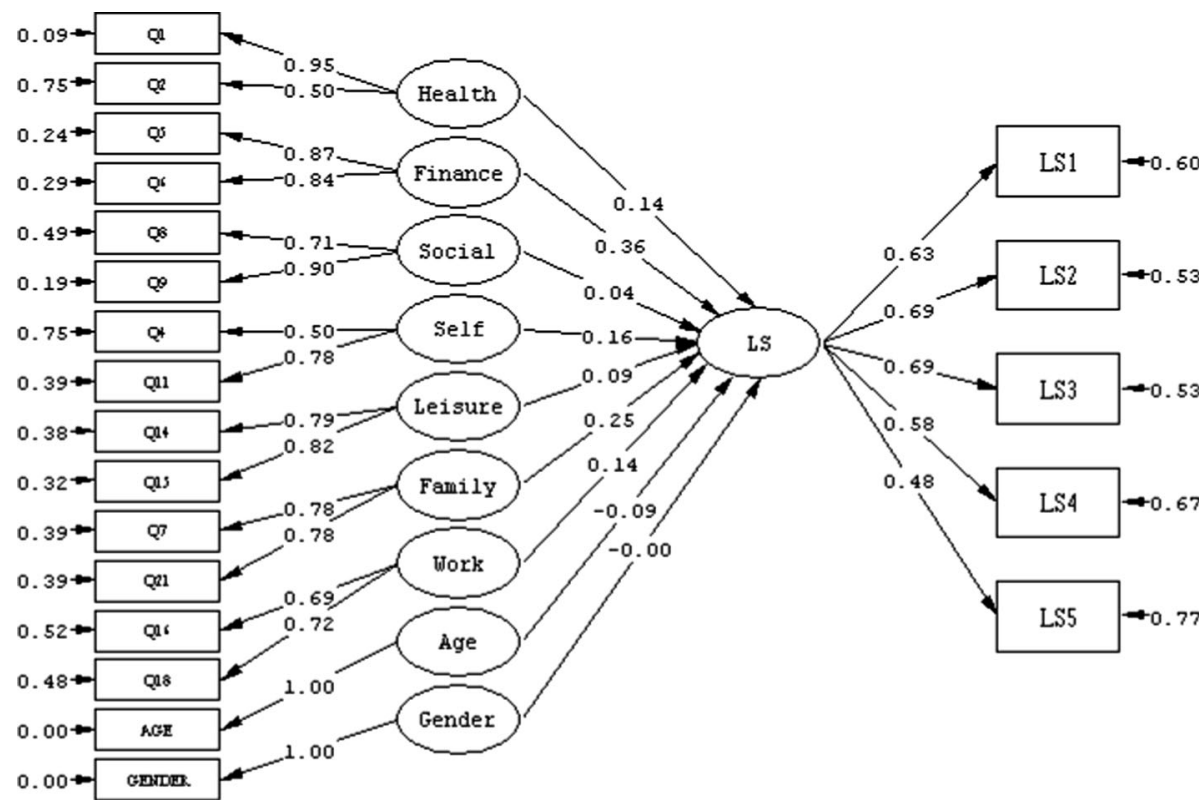

Fig. 1 Standardised solution

Of the seven domain satisfactions, finance, family, health, and work had statistically significant effects on overall life satisfaction. In contrast, social, leisure, and self were shown to be non-significant predictors, with t values of $.79,1.70$, and 1.79 , respectively. While gender effect was not significant, age showed a negative effect on the degree of life satisfaction. To further investigate the non-significant coefficients, we examined multicollinearity. Multicollinearity causes estimation difficulties if life domains are highly correlated as a group, making it difficult to separate the distinct influence of individual predictors (Diamantopoulos and Winklhofer 2001; Diamantopoulos et al. 2008). Table 4 reports the correlations among life domains and variance inflation factors. The correlation matrix showed low-to-moderate correlations among domains. The largest correlations 
occurred between self and social with other domains. In turn, variance inflation factors (VIF) shown in Table 4 were all low, or near, to two, suggesting that multicollinearity was not an important issue (Petter et al. 2007). These results made us safely conclude that we could interpret the estimated coefficients and significance tests.

Finally, common method variance was assessed. A Harman's single-factor test of common method variance (Podsakoff and Organ 1986; Podsakoff et al. 2003) in SPSS revealed seven distinct factors with eigenvalues above 1.0, explaining $59.1 \%$ total variance. The first factor explained $28 \%$ of the variance, which was considered acceptable for a study such as this, where the spillover occurs between life domains. To further assess common method variance, confirmatory factor analysis was applied to Harman's singlefactor model (Sanchez and Brock 1996). The model's fit indices $\left(\chi^{2}=919 ; d f=151\right.$; $\chi^{2} / d f=6 ;$ RMSEA $=.098 ;$ SRMR $\left.=.079 ; \mathrm{CFI}=.889 ; \mathrm{NFI}=.870\right)$ were unacceptable and significantly worse than those of the previous measurement model. This indicated that a single factor solution was not acceptable and so the common method variance effect was negligible.

\section{Discussion and Conclusion}

Previous research examining the effects of satisfaction with multiple life domains on overall life satisfaction has usually reported what accounts for about $50 \%$ of the variance in life satisfaction (Andrews and Withey 1976; Campbell 1976; Hart 1999; Near et al. 1984). The nine predictors included in this study explained $70 \%$ of life satisfaction variance. However, not all the domains had the expected effects on life satisfaction. Results indicated that Chilean workers attribute most importance to their financial situation, followed by family, work, and health. The effects of satisfaction with one's self-worth and leisure-time-although not significant at .05-both had associated t values near the critical value. Satisfaction with social relationships did not seem to be a relevant factor for Chilean workers.

These results are consistent with previous research that found that satisfaction with income, or financial situation, was a dominant predictor of life satisfaction in emerging economies, where gross national product (GNP) grows rapidly but its level is still far lower from most advanced economies like the US or Western European economies. Saris et al. (1996), for instance, found that satisfaction with income was more strongly related to SWB in Eastern Europe than in Western Europe. Similarly, in the Russian context, Saris (2001) found a 'bottom-up' effect for satisfaction with financial situations-but not for housing and marriage satisfactions. Building on Maslow's (1970) needs hierarchy theory, Saris (2001) claimed that in the emerging economies finance satisfaction might be dominant, while in richer countries the effect of the domain satisfactions of social contacts or marriage on SWB might be significant instead because income levels are sufficiently high that people are no longer unduly worried about finance situation.

Regarding the relatively strong relationship found between satisfaction with family and global life satisfaction - the second strongest predictor-we attribute this result to the collectivistic orientation of Chilean culture (Hofstede et al. 2010). This cultural orientation makes the group, and particularly the family, of primary importance. Although material intergenerational dependence may be weaker for workers than for other nonworking populations, the family model of emotional interdependence characterises collectivistic cultures (Kagitcibasi 1996), where individuals emotionally rely on family and maintaining harmonious family relationships is a central goal. Individualistic and collectivistic cultures 
also differ in their conceptualisation of the self (Diener 2000; Suh et al. 1998). In the former cultures the self is self-contained, isolated, independent, and clearly bounded (Markus and Kitayama 1991; Sampson 1989); while the self is enmeshed, interdependent, and contextualised in the later cultures (Tafarodi and Walters 1999). The non-significance of satisfaction with self-worth in our study may reflect the collectivistic nature of Chilean culture since in a cross-national study, Diener and Diener (1995) found that self-esteem correlated more strongly with life satisfaction in individualistic than in collectivist societies.

When respondents are asked to judge the importance of various domains of their lives, 'good health' usually obtains one of the highest ratings (Campbell 1976). In our study, satisfaction with health had a weaker effect on life satisfaction than found in previous research (e.g., Marmot 2003; Gempp and Thieme 2013). We attribute this weaker effect to the nature of participants in the study. We infer that the workers are relatively healthy and are not suffering severe illnesses or disabilities. When a disabling condition is not severe, people tend to adapt and health domain decreases in importance in priorities (Diener et al. 1999). This lower value given for health could, in turn, result in a lower weight of satisfaction with health in overall satisfaction (Oishi et al. 1999). However, this is speculation and needs to be further researched.

The effect of work satisfaction on overall life satisfaction was in the range found in previous research, when the effects of satisfaction in non-work domains were controlled (Rice et al. 1980; Tait et al. 1989; Bowling et al. 2010). Despite the fact that for most adults work is a central task to which they devote a large amount of time and energy, conclusions from meta-analysis studies indicate that work satisfaction is only moderately related to global life satisfaction (Tait et al. 1989; Bowling et al. 2010). Rice et al. (1980) suggested a disaggregation hypothesis of work and life satisfaction, which proposes that the relationship is stronger for individuals who value work in their lives.

Surprisingly, both the effect of satisfaction with social life and leisure-time were nonsignificant - although in different degrees. While satisfaction with leisure-time was nearly significant, satisfaction with social life was clearly not relevant. According to Kitayama and Markus (2000), SWB comes from social participation, which can take different forms. In the case of workers, social participation may take place primarily at work. Harlow and Cantor (1996) found that social participation was a stronger predictor of life satisfaction for retirees than for elders who still hold a job, concluding that social participation was more important for life satisfaction during stages when the opportunity for social interaction was limited by the loss of a job.

Our results also showed that age had a negative effect on life satisfaction. This seemingly paradoxical effect may be explained by the quadratic pattern that previous research has found to characterise the relationship between age and life satisfaction, which reaches its lowest point at middle age but then increases into later adulthood (Blanchflower and Oswald 2008; Kimberly et al. 2012; Löckenhoff and Carstensen 2004). SWB generally does not decline again until after the age of seventy (Baird et al. 2010). Graham and Pettinato (2001) found that Latin America is not different from other economies in this matter. These authors found that happiness had a quadratic relationship with age, initially decreasing, and then increasing monotonically after 49 years of age. Given that our sample was made of workers, the negative effect we found is indicative of the initial decline of life satisfaction in early adulthood. Regarding gender, our results are similar to Graham and Pettinato (2001), who found no significant gender effect for Latin America countries, in contrast to more advanced industrial countries such as the US where women usually tend to be slightly happier than men. 
Three main limitations are worth noting in this study. First, we only considered the direct effects of life domain satisfactions on overall life satisfaction. However, life domains are rarely disconnected from each other. Domains tend to interact with each other in different ways (Wilensky 1960). The spillover model posits that life domain satisfactions are positively related and that satisfaction in one domain affects the others. The compensatory model states that a negative relation exists among domain satisfactions because people compensate for negative experiences in one domain by enriching the others $(\mathrm{Wu}$ 2009). Judge and Watanabe (1994) found that spillover characterised most of the individuals; however, some authors do not agree with this conclusion (Hart 1999). Secondly, we assumed an additive relationship between the life domain satisfactions and overall life satisfaction, although more flexible types of relationships have been proposed. For example, Rojas (2006) argued that there could be substantial gains in the understanding of the relationship by assuming alternative specifications such as an additive relationship, a semi-logarithm relationship, a logarithm-logarithm relationship, or a constant elasticity of substitution (CES) relationship. In particular, Rojas suggested that a CES specification is preferable if the objective is to understand rather than to predict life satisfaction. Finally, the measure development process reduced the number of indicators per life domain to two. As Kline (1998, p. 358) argued: 'having only two indicators per factor may lead to problems. Such models may be more likely to be empirically under identified than models with at least three indicators per factor...part of the model where some factors have only two indicators per factor are not self-sufficient in terms of the covariance matrix.'

\section{References}

Alfonso, C., Allison, D. B., Rader, D. E., \& Gorman, B. S. (1996). The extended satisfaction with life scale: Development and psychometric properties. Social Indicators Research, 38(3), 275-301.

Andrews, F. M., \& Inglehart, R. D. (1979). The structure of psychological well-being in nine western societies. Social Indicators Research, 6, 73-90.

Andrews, F. M., \& Withey, S. B. (1976). Social indicators of well-being: Americans' perceptions of life quality. New York: Plenum.

Argyle, M. (2001). The psychology of happiness. London: Routledge.

Baird, B., Lucas, R. E., \& Donnellan, M. B. (2010). Life satisfaction across the lifespan: Findings from two nationally representative panel studies. Social Indicators Research, 99, 183-203.

Batista, J. M., \& Coenders, G. (2000). Modelos de Ecuaciones Estructurales. La Muralla.

Blanchflower, D. G., \& Oswald, A. J. (2008). Is well-being U-shaped over the life cycle? Social Science and Medicine, 66, 1733-1749.

Bollen, K. A. (1989). Structural equations with latent variables. New York: Wiley.

Bowling, N. A., Eschleman, K. J., \& Wang, Q. (2010). A meta-analytic examination of the relationship between job satisfaction and subjective well-being. Journal of Occupational and Organizational Psychology, 83, 915-934.

Breslin, R. W. (1970). Back-translation for cross-cultural research. Cross-Cultural. Psychology, 1, $185-216$.

Bretones, F. D., \& Gonzalez, M. J. (2011). Subjective and occupational well-being in a sample of mexican workers. Social Indicators Research, 100, 273-285.

Brief, A. P., Butcher, A. H., George, J. M., \& Link, K. E. (1993). Integrating bottom-up and top-down theories of subjective well-being: The case of health. Journal of Personality and Social Psychology, 64, 646-653.

Brown, P. H., \& Tierney, B. (2009). Religion and subjective well-being among the elderly in China. The Journal of Socio-Economics, 38, 310-319.

Campbell, A. (1976). Subjective measures of well-being. American Psychologist, 31, 177-223.

Cantor, N., \& Blanton, H. (1996). Effortful pursuit of personal goals in daily life. In J. A. Bargh \& P. M. Gollwitzer (Eds.), The psychology of action: Linking cognition and motivation to behavior (pp. 338-359). New York: Guilford. 
Cantor, N., \& Sanderson, C. A. (1999). Life task participation and well-being: The importance of taking part in daily life. In D. Kahneman, E. Diener, \& N. Schwarz (Eds.), Well-being: The foundations of hedonic psychology. New York: Russell Sage Foundation.

Costa, S. (2008). Quality of life in remote mining communities: A multiple case study in the Brazilian Amazon, Dissertation, The University of British Columbia (Vancouver).

Cummins, R. A. (1996). The domains of life satisfaction: An attempt to order chaos. Social Indicators Research, 38, 303-332.

Cummins, R. A., Eckersley, R., Pallant, J., Van Vugt, J., \& Misajon, R. (2003). Developing a national index of subjective wellbeing: The Australian unity wellbeing index. Social Indicators Research, 64, $159-190$.

Day, R. L. (1987). Relationships between life satisfaction and consumer satisfaction. In A. Coskun Samli (Ed.), Marketing and the quality of life interface. New York: Quorum Books.

De Cuyper, N., Notelaers, G., \& De Witte, H. (2009). Transitioning between temporary and permanent employment: A two-wave study on the entrapment, the stepping stone and the selection hypothesis. Journal of Occupational and Organizational Psychology, 82, 67-88.

DeNeve, K. M., \& Cooper, H. (1998). The happy personality: A meta-analysis of 137 personality traits and subjective well-being. Psychological Bulletin, 124, 197-229.

Diamantopoulos, A., Reifler, P., \& Roth, K. P. (2008). Advancing formative measurement models. Journal of Business Research, 61, 1203-1218.

Diamantopoulos, A., \& Winklhofer, H. M. (2001). Index construction with formative indicators: An alternative to scale development. Journal of Marketing Research, 38, 269-277.

Diener, E. (1984). Subjective well-being. Psychological Bulletin, 95, 542-575.

Diener, E. (1994). Assessing subjective well-being: Progress and opportunities. Social Indicators Research, 31, 103-157.

Diener, E. (1996). Traits can be powerful, but are not enough: Lessons from subjective well-being. Journal of Research in Personality, 30, 389-399.

Diener, E. (2000). Subjective well-being: The science of happiness and a proposal for a national index. The American Psychologist, 55, 34-43.

Diener, E., \& Diener, M. (1995). Cross-cultural correlates of life satisfaction and self-esteem. Journal of Personality and Social Psychology, 68, 653-663.

Diener, E., Emmons, R. A., Larsen, R. J., \& Griffin, S. (1985). The satisfaction with life scale. Journal of Personality Assessment, 49, 71-75.

Diener, E., \& Lucas, R. E. (2000). Explaining differences in societal levels of happiness: relative standards need fulfillment, culture, and evaluation theory. Journal of Happiness Studies, 1, 41-78.

Diener, E., Oishi, S., \& Lucas, R. E. (2003). Personality, culture, and subjective well-being: Emotional and cognitive evaluations of life. Annual Review of Psychology, 54, 403-425.

Diener, E., \& Suh, E. M. (2000). Culture and subjective well-being. Cambridge, MA: MIT.

Diener, E., Suh, E. M., Lucas, R. E., \& Smith, H. L. (1999). Subjective well-being: Three decades of progress. Psychological Bulletin, 125, 276-302.

Duckworth, A. L., Quinn, P. D., \& Seligman, M. E. P. (2009). Positive predictors of teacher effectiveness. Journal of Positive Psychology, 4, 540-547.

Durak, M., Senol-Durak, E., \& Gencoz, T. (2010). Psychometric properties of the satisfaction with life scale among Turkish university students, correctional, officers, and elderly adults. Social Indicators Research, 99, 413-429.

Erdogan, B., Bauer, T. N., Truxillo, D. M., \& Mansfield, L. R. (2012). Whistle while you work: A review of the life satisfaction literature. Journal of Management, 38, 1038-1083.

Felce, D., \& Perry, J. (1995). Quality of life and its definition and measurement. Research in Developmental Disabilities, 16, 51-74.

Fishbein, M., \& Ajzen, I. (1974). Attitudes towards objects as predictors of single and multiple behavioral criteria. Psychological Review, 81, 59-74.

Flanagan, J. C. (1978). A research approach to improving our quality of life. American Psychologist, 33, $138-147$.

Fornell, C., \& Larcker, D. F. (1981). Evaluating structural equation models with unobservable variables and measurement error. Journal of Marketing Research, 18, 39-50.

Gadermann, A. M., Guhn, M., \& Zumbo, B. D. (2011). Investigating the substantive aspect of construct validity for the satisfaction with life scale adapted for children: A focus on cognitive processes. Social Indicators Research, 100, 37-60.

Gempp, R., \& Thieme, C. (2013). Satisfacción con la vida y satisfacción laboral en trabajadores chilenos: La importancia del liderazgo. Word of Business Ideas, 15, 8-14. 
Gilman, R. S., \& Huebner, E. S. (2000). Review of life satisfaction measures for adolescents. Behavior Change, 17, 178-195.

Graham, C., \& Pettinato, S. (2001). Happiness, markets, and democracy: Latin America comparative perspective. Journal of Happiness Studies, 2, 237-268.

Greenley, J. R., Greenberg, J. S., \& Brown, R. (1997). Measuring quality of life: A new and practical survey instrument. Social Work, 42(3), 244-254.

Gregg, P. M., \& Salisbury, P. S. (2001). Confirming and expanding the usefulness of the extended satisfaction with life scale (ESWLS). Social Indicators Research, 54, 1-16.

Greguras, G. J., \& Diefendorff, J. M. (2010). Why does proactive personality predict employee life satisfaction and work behaviors? A field investigation of the mediating role of the self-concordance model. Personnel Psychology, 63, 539-560.

Haar, J. M., \& Roche, M. A. (2010). Family supportive organization perceptions and employee outcomes: The mediating effects of life satisfaction. International Journal of Human Resource Management, 21, 999-1014.

Hair, J. F., Black, W. C., Babin, B. J., Anderson, R. E., \& Tatham, R. L. (2006). Multivariate data analysis (6th ed.). Upper Saddle River, NJ: Prentice-Hall.

Harlow, R. E., \& Cantor, N. (1996). Still participating after all these years: A study of life task participation in later life. Journal of Personality and Social Psychology, 71, 1235-1249.

Hart, P. M. (1999). Predicting employee life satisfaction: A coherent model of personality, work and nonwork experiences, and domain satisfactions. Journal of Applied Psychology, 84, 564-584.

Headey, B., Veenhoven, R., \& Wearing, A. (1991). Top-down versus bottom-up theories of subjective wellbeing. Social Indicators Research, 24, 81-100.

Headey, B., \& Wearing, A. (1992). Understanding happiness: A theory of subjective well-being. Melbourne, Australia: Longman Cheshire.

Heine, S. J., Lehman, D. R., Markus, H. R., \& Kitayama, S. (1999). Is there a universal need for positive selfregard? Psychological Review, 106, 766-794.

Heller, D., Watson, D., \& Ilies, R. (2004). The role of person versus situation in life satisfaction: A critical examination. Psychological Bulletin, 130, 574-600.

Hinkin, T. R. (1995). A review of scale development practices in the study of organizations. Journal of Management, 21, 967-988.

Hinkin, T. R., \& Tracey, J. B. (1999). An analysis of variance approach to content validation. Organizational Research Methods, 2(2), 175-186.

Hofstede, G. (1991). Cultures and organizations: Software of the mind. London: McGraw-Hill.

Hofstede, G., Hofstede, G. J., \& Minkov, M. (2010). Cultures and Organizations: Software of the Mind: Intercultural cooperationand its importance for survival (3rd Ed.). McGrw-Hill.

Hu, L. T., \& Bentler, P. M. (1999). Cutoff criteria for fit indexes in covariance structure analysis: Conventional criteria versus new alternatives. Structural Equation Modeling, 6, 1-55.

Hu, L. T., Bentler, P. M., \& Kano, Y. (1992). Can test statistics in covariance structure analysis be trusted? Psychological Bulletin, 112, 351-362.

Huebner, E. S. (1994). Preliminary development and validation of a multidimensional life satisfaction scale of children. Psychological Assessment, 6, 149-158.

Jones, M. D. (2006). Which is a better predictor of job performance: Job satisfaction or life satisfaction. Journal of Behavioral and Applied Management, 8, 20-42.

Jöreskog, K. G., \& Sörbom, D. (2001). Lisrel 8: User's reference guide. Chicago: Scientific Software International.

Judge, T. A., \& Locke, E. A. (1993). Effect of dysfunctional thought processes on subjective well-being and job satisfaction. Journal of Applied Psychology, 78, 475-490.

Judge, T. A., \& Watanabe, S. (1994). Individual differences in the nature of the relationship between job and life satisfaction. Journal of Occupational and Organizational Psychology, 67, 101-107.

Kagitcibasi, C. (1996). Family and human development across cultures: A view from the other side. Hillside: Lawrence Erlbaum.

Kahneman, D., Krueger, A. B., Schkade, D., Schwarz, N., \& Stone, A. A. (2006). Would you be happier if you were richer? A focusing illusion. Science, 312, 1908-1910.

Kasser, T., \& Ryan, R. M. (1993). A dark side of the American dream: Correlates of financial success as a central life aspiration. Journal of Personality and Social Psychology, 65, 410-422.

Kasser, T., \& Ryan, R. M. (1996). Further examining the American dream: Differential correlates of intrinsic and extrinsic goals. Personality and Social Psychology Bulletin, 22, 280-287.

Kim, U. (1994). Individualism and collectivism: Conceptual clarification and elaboration. In U. Kim, H. Triandis, C. Kagitcibasi, et al. (Eds.), Individualism and collectivism: Theory, method, and application (pp. 19-40). CA: Sage Beverly Hills. 
Kimberly, McAdams, K., Lucas, R. E., \& Donnellan, M. B. (2012). The role of domain satisfaction in explaining the paradoxical association between life satisfaction and age. Social Indicators Research, 109, 295-303.

Kitayama, S., \& Markus, H. R. (2000). The pursuit of happiness and the realization of sympathy: Cultural patterns of self, social relations, and well-being. In E. Diener \& E. M. Suh (Eds.), Cultural and subjective well-being (pp. 113-161). Cambridge, MA: MIT.

Kline, R. B. (1998). Principles and Practice of Structural Equation Modeling. New York: The Guilford.

Ku, P., Fox, K. R., \& McKenna, J. (2008). Assessing Subjective Well-being in Chinese Older Adults: The Chinese Aging Well Profile. Social Indicators Research, 87, 445-460.

Lance, C. E., Lautenschlager, G. J., Sloan, C. E., \& Varca, P. E. (1989). A comparison between bottom-up, top-down, and bidirectional models of relationship between global and life facet satisfaction. Journal of Personality, 57, 601-624.

Löckenhoff, C. E., \& Carstensen, L. L. (2004). Socioemotional selectivity theory, aging, and health: The increasingly delicate balance between regulating emotions and making tough choices. Journal of Personality, 72, 1395-1424.

MacKenzie, S. B., Podsakoff, P. M., \& Podsakoff, N. P. (2011). Construct measurement and validation procedures in MIS and behavioral research: Integrating new and existing techniques. MIS Quarterly, $35,293-334$.

Mardia, K. V. (1974). Applications of some measures of multivariate skewness and kurtosis in testing normality and robustness studies. Sankhya B, 36, 115-118.

Markus, H. R., \& Kitayama, S. (1991). Culture and the self: Implications for cognition, emotion, and motivation. Psychological Review, 98, 224-253.

Marmot, M. (2003, June). The social gradient in health and well-being. Paper presented at the Brookings Warwick Conference Why inequality matters: Lessons for policy from the economics of happiness, Washington, DC.

Maslow, A. H. (1970). Motivation and personality (3rd ed.). New York: Harper \& Row.

Matthews, M., Zullig, K. J., Ward, R. M., Horn, T., \& Huebner, E. S. (2012). An analysis of specific life satisfaction domains and disordered eating among college students. Social Indicators Research, 107, 55-69.

Michalos, A. C. (1985). Multiple discrepancies theory (MDT). Social Indicators Research, 16, 347-413.

Möller, V., \& Saris, W. E. (2001). The relationship between subjective wellbeing and domain satisfactions in South Africa. Social Indicators Research, 55, 97-114.

Murphy, S. A., Duxbury, L., \& Higgins, C. (2006). The individual and organizational consequences of stress, anxiety, and depression in the workplace: A case study. Canadian Journal of Community Mental Health, 25, 143-157.

Near, J. P., Smith, C. A., Rice, R. W., \& Hunt, R. G. (1984). A comparison of work and nonwork predictors of life satisfaction. Academy of Management Journal, 27, 184-190.

Nunnally, J. C., \& Bernstein, I. H. (1994). Psychometric Theory (3rd ed.). New York: McGraw Hill.

Oishi, S. (2006). The concept of life satisfaction across cultures: An IRT analysis. Journal of Research in Personality, 40, 411-423.

Oishi, S., Diener, E., Suh, E., \& Lucas, R. E. (1999). Value as a moderator in subjective well-being. Journal of Personality, 67, 157-184.

Olinsky, A., Chen, S., \& Harlow, L. (2003). The comparative efficacy of imputations methods for missing data in structural equation modeling. European Journal of Operational Research, 151, 53-79.

Pavot, W., \& Diener, E. (1993). Review of the satisfaction with life scale. Psychological Assessment, 5, 164-172.

Pavot, W., \& Diener, E. (2008). The satisfaction with life scale and the emerging construct of life satisfaction. Journal of Positive Psychology, 3, 137-152.

Petter, S., Straub, D., \& Rai, A. (2007). Specifying formative constructs in information systems research. MIS Quarterly, 31, 623-656.

Podsakoff, P. M., MacKenzie, S. B., Lee, J. Y., \& Podsakoff, N. P. (2003). Common method bias in behavioral research: A critical review of the literature and recommended remedies. Journal of Applied Psychology, 88, 879-903.

Podsakoff, P. M., \& Organ, D. W. (1986). Self-reports of organizational research: Problems and prospects. Journal of Management, 12, 531-544.

Pons, D., Atienza, F. L., Balaguer, I., \& Garcia-Merita, M. L. (2002). Propiedades psicométricas de la escala de satisfacción con la vida en personas de tercera edad [Psychometric properties of satisfaction with life scale in the elderly]. Revista Iberoamericana de Diagnóstico y Evaluación Psicológica, 13, 71-82.

Praag, B., Frijtersvan, P., \& Ferrer-i-Carbonell, A. (2003). The anatomy of subjective well-being. Journal of Economic Behavior \& Organization, 51, 29-49. 
Redman, T., \& Snape, E. (2006). The consequences of perceived age discrimination amongst older police officers: Is social support a buffer? British Journal of Management, 17, 167-175.

Rice, R. W., Near, J. P., \& Hunt, R. G. (1980). The job satisfaction-life satisfaction relationship: A review of empirical research. Basic and Applied Social Psychology, 1, 37-64.

Rojas, M. (2006). Life satisfaction and satisfaction in domains of life: Is it a simple relationship? Journal of Happiness Studies, 7, 467-497.

Roth, P. L. (1994). Missing data: A conceptual review for applied psychologists. Personnel Psychology, 47, 537-559.

Sampson, E. E. (1989). The challenge of social change for psychology: Globalization and psychology's theory of person. American Psychologist, 44, 914-921.

Saris, W. E. (2001). What influences subjective well-being in Russia? Journal of Happiness Studies, 2, $137-146$.

Saris, W. E., \& Galhofer, I. N. (2007). Design, evaluation, and analysis of questionnaires for survey research. Hoboken, NJ: Wiley, Inc.

Saris, W. E., Veenhoven, R., Scherpenzeel, A. C., \& Bunting, B. (1996). A comparative study of life satisfaction in Europe. Budapest: Eötvös University Press.

Satorra, A., \& Bentler, P. M. (1994). Corrections to test statistics and standard errors in covariance structure analysis. In A. Von Eye \& C. Clogg (Eds.), Latent variables analysis: Applications to developmental research (pp. 399-419). Thousand Oaks: Sage.

Seligson, J. L., Huebner, E. S., \& Valois, R. F. (2003). Preliminary validation of the brief multidimensional student's life satisfaction scale. Social Indicators Research, 61, 121-145.

Shaw, J. D., \& Gupta, N. (2001). Pay fairness and employee outcomes: Exacerbation and attenuation effects of financial need. Journal of Occupational and Organizational Psychology, 74, 299-320.

Sheldon, K. M., \& Elliot, A. J. (1999). Goal striving, need satisfaction, and longitudinal well-being: The self-concordance model. Journal of Personality and Social Psychology, 76, 482-497.

Sirgy, M. J., Widgery, R. N., Lee, D., \& Yu, G. B. (2010). Developing a measure of community well-being based on perceptions of impact in various life domains. Social Indicators Research, 96, 295-311.

Steel, P., Schmidt, J., \& Shultz, J. (2008). Refining the relationship between personality and subjective wellbeing. Psychological Bulletin, 134, 138-161.

Suh, E., Diener, E., Oishi, S., \& Triandis, H. C. (1998). The shifting basis of life satisfaction.judgments across cultures: Emotions versus norms. Journal of Personality and Social Psychology, 74, 482-493.

Susskind, A. M., Borchgrevink, C. P., Kacmar, K. M., \& Brymer, R. A. (2000). Customer service employees' behavioral intentions and attitudes: An examination of construct validity and a path model. International, Journal of Hospitality Management, 19, 53-77.

Tafarodi, R., \& Walters, P. (1999). Individualism-collectivism, life events, and self-esteem: A test of two trade-offs. European Journal of Social Psychology, 29, 797-814.

Tait, M., Padgett, M. Y., \& Baldwin, T. T. (1989). Job and life satisfaction: A re-examination of the strength of the relationship and gender effects as a function of the date of the study. Journal of Applied Psychology, 74, 502-507.

Triandis, H. C. (1989). The self and social behavior in differing cultural contexts. Psychological Review, 96, $506-520$.

UNDP Human Development in Chile (2012). Bienestar subjetivo: el desafío de repensar el desarrollo. United Nations Development Programme. http://www.desarrollohumano.cl/.

UNDP Human Development Report. (2013). The rise of the south: human progress in a diverse world. United Nations Development Programme.

Vanaki, Z., \& Vagharseyyedin, S. A. (2009). Organizational commitment, work environment conditions, and life satisfaction among Iranian nurses. Nursing \& Health Sciences, 11, 404-409.

Vassar, M. (2008). A note on the score reliability for the Satisfaction With Life Scale: An RG study. Social Indicators Research, 86, 47-57.

Veenhoven, R. (1996). Developments in satisfaction research. Social Indicators Research, 37, 1-45.

Von Bonsdorff, M. E., Huuhtanen, P., Tuomi, K., \& Seitsamo, J. (2010). Predictors of employees' early retirement intentions: An 11-year longitudinal study. Occupational Medicine, 60, 94-100.

Wilensky, H. L. (1960). Work, careers, and social integration. International Social Science Journal, 12, $543-560$.

Wu, C. H. (2009). Enhancing quality of life by shifting importance perception among life domains. Journal of Happiness Studies, 10, 37-47.

Zapf, W., \& Glatzer, W. (1987). German social report: living conditions and subjective well-being, (1978-1984). Social Indicators Research, 19, 1-17. 